\title{
EVALUASI KUALITAS VISUAL DAN FUNGSIONAL RUMPUT LAPANGAN SEPAKBOLA
}

\section{Evaluation of Visual and \\ Fuctional Qualities of Soccer Field's Grass}

\section{E Junathan Muakhor \\ Staf Pengajar Fakultas Pertanian \\ Universitas Tribuwana Tunggadewi \\ Nizar Nasullah \\ Staff Pengajar Departemen Arsitektur Lanskap Fakultas Pertanian IPB}

\section{Afra DN Makalew}

Staff Pengajar Departemen Arsitektur Lanskap Fakultas Pertanian IPB

\begin{abstract}
Soccer is one of the popular sport around the world. Nowaday, Indonesia has more or less 170 soccer fields. Soccer requires fileds with excellent turfgrass which comply quality standards. This study was aimed to evaluate visual and functional qualities of soccer field, and propose recommendations related to management of soccer field that can fulfill visual and functional qualities. This study was conducted at three soccer stadiums namely Gelora Bung Karno Stadium (Jakarta), Si Jalak Harupat Stadium (Bandung), and Maguwoharjo Stadium (Yogyakarta). Survey and sampling methods were used together with interview method. Sampling based on parameter of visual and functional qualities. Then, analyzed by compare the data with standard quality. Planting medium and leaves samples has taken to laboratory analyzed. Grass quality of Maguwoharjo Stadium has the lowest quality than the others because the shortage of fertilizer condition in planting medium. Consequently, it affected grass growth and performance. Bades on the existing problems, some improvements of planting medium fertility were needed to get the optimal growth and performance in Maguwoharjo Stadium, such as adding the lime and compost or zeolit into planting media to increase the soil $\mathrm{pH}$ and CEC (Cation Exchange Capacity).
\end{abstract}

Keywords: Fertilizing, mowing, planting medium, soccer grass field, visual and functional qualities

\section{PENDAHULUAN}

Permainan sepakbola merupakan salah satu jenis olahraga yang sudah populer di seluruh dunia. Saat ini, di Indonesia terdapat kurang lebih 170 buah lapangan sepakbola, baik yang berupa stadion maupun gelanggang olahraga, dan sebagian memiliki fungsi lain (multi use). Olahraga ini membutuhkan kondisi lapangan yang prima, selain dari perfomance para pemain itu sendiri. Lapangan sepakbola harus memenuhi kualitas standar. Masalah terkait dengan rumput lapangan sepakbola yang terjadi di Indonesia yaitu kesesuaian pemilihan jenis rumput, media tanam, dan pertumbuhan rumput yang dipengaruhi kondisi iklim dan ketersediaan nutrisinya.

Salah satu teknik untuk menghasilkan kondisi rumput yang prima yaitu dengan memberikan pupuk untuk meningkatkan performa rumput. Emmons (2000) menyebutkan bahwa rumput membutuhkan nitrogen $(\mathrm{N})$, fosfor $(\mathrm{P})$, dan kalium (K) dalam jumlah besar dibanding jenis nutrisi lainnya. Perbandingan jumlah pupuk yang tepat diberikan tergantung pada jumlah nutrisi yang tersedia dalam tanah. Jumlah fosfor dan kalium yang tersedia dalam tanah dapat diketahui melalui uji tanah. Hasil uji tanah dimanfaatkan oleh pengelola rumput untuk menentukan kegiatan pemupukan yang efektif dan efisien. Saat ini banyak terjadi kerusakan kondisi lapangan rumput yang salah satunya disebabkan oleh pemberian komposisi nutrisi yang tidak tepat. Pemberian pupuk $\mathrm{N}$ pada tingkat dan frekuensi yang sesuai kebutuhan rumput dapat menurunkan kehilangan $\mathrm{N}$ dari lapangan rumput (Barton dan Colmer 2005).

Menurut Puhalla et al (1999), respon bola merupakan faktor paling penting dalam permainan sepakbola. Pengelola lapangan harus memilih jenis spesies rumput yang baik dan cara budidaya yang tepat dengan pemangkasan yang pendek, serta harus mempertimbangkan kebutuhan waktu yang tepat untuk memangkas. Melihat kondisi Indonesia yang berada di wilayah tropis dengan tingkat curah hujan cukup tinggi maka memicu pertumbuhan tanaman yang lebih cepat. Diperlukan teknik pemangkasan yang tepat untuk menjaga kualitas rumput tetap prima. Tujuan penelitian ini yaitu: 1) menganalisis pengaruh perbedaan komposisi media tanam, pemupukan, dan pemangkasan terhadap pertumbuhan rumput ditinjau dari kualitas visual dan fungsional rumput lapangan sepakbola, 2) mengevaluasi kualitas visual dan fungsional ketiga lapangan sepakbola, dan 3) memberikan rekomendasi pengelolaan lapangan sepakbola terkait media tanam, pemupukan, dan pemangkasan yang dapat menghasilkan performa prima lapangan sepakbola.

\section{METODE PENELITIAN}

\section{Waktu dan Lokasi}

Penelitian ini dilakukan pada Bulan Januari hingga Maret 2013. Lapangan sepakbola yang dipilih yaitu lapangan yang menggunakan jenis rumput manila (Zoysia matrella). Ketiga lapangan yang dipilih sebagai lokasi survei yaitu Gelora Bung Karno (Jakarta), Stadion Sleman (Yogyakarta), dan Stadion Si Jalak Harupat (Bandung).

\section{Bahan dan Alat}

Bahan dan alat yang digunakan dalam penelitian ini antara lain: bola kaki, gunting, meteran, kuadran sampel, penggaris, ring sampler, Munsell color chart, hole cutter, cooler box, dan kamera DSLR.

\section{Metode Penelitian}

Pengambilan data dilakukan dengan dua cara, yaitu wawancara dan pengamatan langsung dengan 
parameter seperti pada Tabel 1 . Parameter pengamatan dibedakan menjadi dua, yaitu parameter kualitas visual (Tabel 2) dan parameter kualitas fungsional (Tabel 3). Selanjutnya, hasil pengamatan dianalisis dengan membandingkan dengan standar-standar kualitas rumput lapangan sepakbola hasil studi literatur seperti ditunjukkan dalam Tabel 4.

\section{KONDISI UMUM}

\section{Iklim}

Data iklim dari ketiga lokasi survei stadion diperoleh melalui data sekunder. Berdasarkan sumber data pada tahun 2012, diketahui ketiga lokasi stadion memiliki karakter iklim yang berbeda. Pada Tabel 5 dapat dilihat data iklim pada ketiga lokasi survei penelitian. Kondisi iklim ini akan mempengaruhi pertumbuhan dan teknik pengelolaan rumput lapangan sepakbola, terutama saat pelaksanaan penyiraman rumput. Terdapat tiga faktor penting yang berpengaruh terhadap permukaan lapangan sepakbola, yaitu kondisi permukaan, pemain, dan interaksi bola. Kondisi permukaan lapangan dipengaruhi oleh lingkungan, jenis lapangan, lokasi geografis, dan pengelolaan lapangan (Ronkainen et al. 2012). Stadion Si Jalak Harupat yang berada di Kabupaten Bandung yang memiliki tingkat curah hujan cukup tinggi sehingga membutuhkan tingkat penyiraman yang lebih rendah dibandingkan dengan dua stadion yang lainnya. Kabupaten Sleman yang memiliki curah hujan rendah maka rumput Stadion Maguwoharjo membutuhkan penyiraman yang lebih intensif dibandingkan dua stadion yang lainnya. Tingkat curah hujan pada suatu daerah juga akan mempengaruhi pertumbuhan rumput lapangan sepakbola, semakin tinggi curah hujan semakin cepat pertumbuhan rumput. Hal ini akan mempengaruhi intensitas perawatan yang harus dilakukan, seperti pemangkasan.

\begin{tabular}{|lcc|}
\hline \multicolumn{3}{c}{ Tabel 1 Kegiatan wawancara dan parameter amatan } \\
\hline Wawancara pengelola & Parameter & Keterangan \\
\hline Parameter & - kepadatan rumput, & diambil dari area gawang, back, \\
\hline - jenis media tanam, & - warna rumput, & dan striker kemudian dibandingkan \\
- jenis dan dosis pupuk, & - tekstur rumput, & dengan standar rumput lapangan \\
- waktu pemberian pupuk, & - elastisitas, & sepakbola \\
- intensitas penyiraman, & - perakaran & \\
\cline { 2 - 3 } - intensitas dan ketinggian & - sampel tanah, & diambil dari area gawang, back, \\
pemangkasan, & - sampel daun & dan striker kemudian dilakukan uji \\
- penyakit pada rumput, & & laboratorium \\
- intensitas penggunaan & & \\
\hline
\end{tabular}

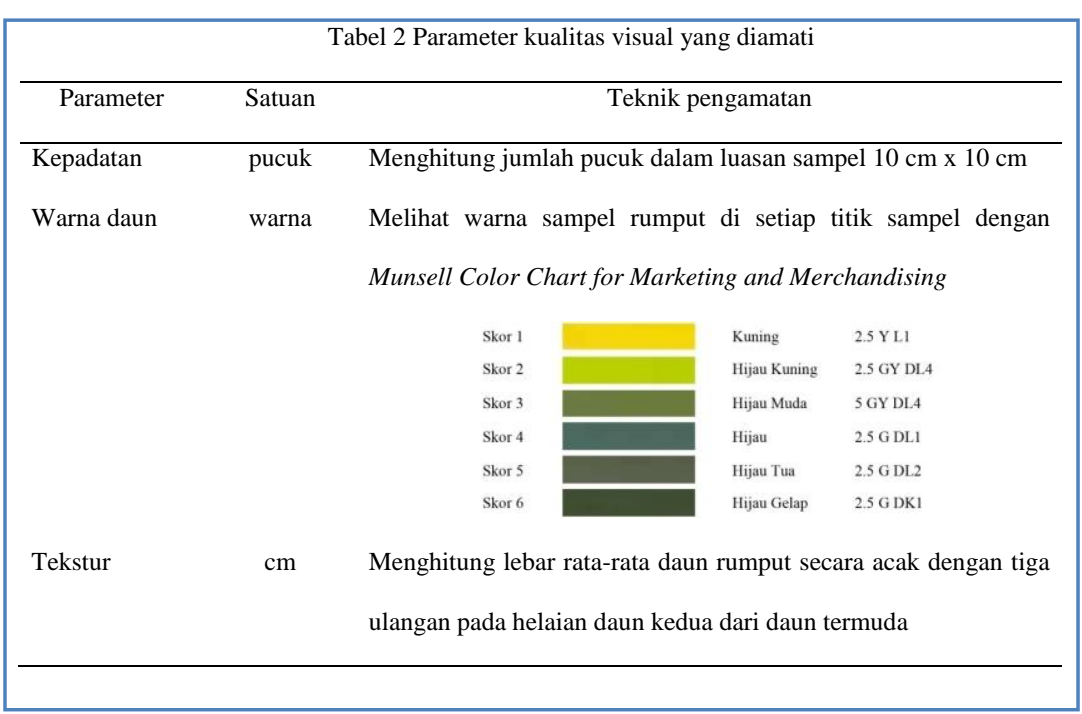

\begin{tabular}{|c|c|c|}
\hline Parameter & Satuan & Teknik amatan \\
\hline Elastisitas & $\mathrm{cm}$ & Mengukur jarak pantulan bola yang dijatuhkan dari ketinggian $2 \mathrm{~m}$ \\
\hline Hasil & & Mengambil sampel pangkasan rumput seluas $10 \mathrm{~cm}$ x $10 \mathrm{~cm}$ kemudian \\
\hline Pangkasan & $\mathrm{g}$ & \\
\hline Perakaran & & Sampel diambil dengan hole sampler $\phi 10 \mathrm{~cm}$ \\
\hline - Panjang akar & $\mathrm{cm}$ & - Panjang akar diukur dengan penggaris \\
\hline - Berat kering & $\mathrm{g}$ & $\begin{array}{l}\text { - Sampel akar dikeringkan dengan suhu } 60^{\circ} \mathrm{C} \text { selama } 24 \text { jam, } \\
\text { kemudian ditimbang }\end{array}$ \\
\hline
\end{tabular}

\begin{tabular}{|cccc|}
\hline \multicolumn{4}{c}{ Tabel 4 Standar penilaian rumput lapangan sepakbola } \\
\hline No & \multicolumn{1}{c}{ Parameter penilaian } & Penilaian baik & \multicolumn{1}{c|}{ Sumber } \\
\hline 1 & Kepadatan per $100 \mathrm{~cm}^{2}$ & $>30$ pucuk & Ayuningtyas (2007) \\
2 & Warna rumput & Hijau tua & Brosnan \& Deputy (2008) \\
3 & Tekstur rumput $(\mathrm{mm})$ & $<2$ & Patton (2010) \\
4 & Berat kering pucuk $\left(\mathrm{gr} / 100 \mathrm{~cm}^{2}\right)$ & $>1,5$ & Fatmasari (2011) \\
5 & Berat kering akar $\left(\mathrm{gr} / 100 \mathrm{~cm}^{2}\right)$ & $>1,5$ & Fatmasari (2011) \\
6 & Panjang akar / root lenght $(\mathrm{cm})$ & $4-15$ & Christians (2004) \\
7 & Jarak pantul bola $(\mathrm{cm})$ & $60-85$ & FIFA (2012) \\
\hline
\end{tabular}
dikelola oleh pihak yang berbeda. 
Namun, ketiga stadion tersebut berada di bawah pengawasan PSSI sebagai organisasi sepakbola di Indonesia. Stadion Gelora Bung Karno dikelola pihak swasta oleh Badan Pengelola Kompleks Gelora Bung Karno. Pihak pengelola memberikan perhatian dan melakukan pengelolaan stadion utama dengan cukup intensif. Selain digunakan untuk pertandingan sepakbola, stadion utama Gelora Bung Karno juga digunakan untuk kegiatan lain, seperti konser musik, acara keagamaan, hingga acara partai politik. Kapasitas penonton di Stadion Gelora Bung Karno sebanyak 88.000 orang.

Stadion Si Jalak Harupat dan Stadion Maguwoharjo dikelola langsung oleh pemerintah daerah (PEMDA) setempat. Stadion Si Jalak Harupat dikelola oleh Pemerintah Daerah Kabupaten Bandung yang ditanggungjawabkan kepada Dinas Pemuda, Olahraga dan Pariwisata (DISPOPAR) Kabupaten Bandung. Stadion Si Jalak Harupat memiliki kapasitas penonton sebanyak 40.000 orang. Stadion Maguwoharjo dikelola oleh Pemerintah Daerah Kabupaten Sleman yang ditanggungjawabkan kepada Komite Olahraga Nasional Indonesia (KONI) Kabupaten Sleman. Stadion Maguwoharjo memiliki kapasitas penonton sebanyak 40.000 orang. Masing-masing Unit Pengelola Terpadu (UPT) dari ketiga stadion memiliki sistem dan teknik pengelolaan lapangan yang berbeda.

\section{HASIL DAN PEMBAHASAN}

\section{Media Tanam Lapangan}

Pada Stadion Gelora Bung Karno, media tanam rumput yang digunakan adalah pasir pasang dan pasir beton. Media tanam rumput yang digunakan pada Stadion Si Jalak Harupat adalah pasir galunggung yang dicampur dengan sekam. Stadion Maguwoharjo menggunakan media tanam pasir pantai. Hasil uji laboratorium media tanam rumput lapangan dapat dilihat pada Tabel 6. Menurut Sutanto (2005) tanah dengan nilai permeabilitas 160-250 mm/jam dan $>250 \mathrm{~mm} / \mathrm{jam}$ termasuk kelas permeabilitas cepat dan sangat cepat. Pada Stadion Gelora Bung Karno dan Stadion Si Jalak Harupat memiliki kelas permeabilias sangat cepat, sedangkan pada Stadion Maguwoharjo memiliki kelas permeabilitas cepat. Perbedaan disebabkan oleh perbedaan media tanam pasir yang digunakan. Nilai permeabilitas dan perkolasi lebih jauh dapat dikaitkan dengan praktik pemupukan. Pada tanah yang memiliki permeabilitas cepat akan mengakibatkan bahan-bahan yang diberikan akan cepat hilang sehingga ketersediaan unsur hara atau nutrisi di dalam tanah karena tanaman menyerap nutrisi dalam bentuk ionion dan semakin besar nilai KTK menunjukkan semakin banyak terjadi pertukaran unsur/nutrisi menjadi ion-ion yang tersedia bagi tanaman. Selain itu, nilai KTK Stadion Si Jalak Harupat cukup tinggi salah satunya dipengarui campuran sekam dalam media tanam. Sekam menjadi sumber pupuk organik. Semakin tinggi konsentrasi pupuk organik yang diberikan pada media tanam, semakin besar pengaruh yang terlihat pada pertumbuhan rumput (Lasamadi et al. 2013)

\begin{tabular}{|c|c|c|c|c|c|}
\hline \multirow{3}{*}{ No } & \multicolumn{5}{|c|}{ Tabel 6 Hasil uji parameter terhadap media tanam } \\
\hline & \multirow{2}{*}{ Parameter } & \multirow{2}{*}{ Satuan } & \multicolumn{3}{|c|}{ Stadion } \\
\hline & & & Gelora Bung Karno & Si Jalak Harupat & Maguwoharjo \\
\hline 1 & $\mathrm{pH}$ & - & 6,60 & 6,60 & 5,40 \\
\hline 2 & KTK & $\mathrm{me} / 100 \mathrm{~g}$ & 11,06 & 16,08 & 3,99 \\
\hline 3 & Bulk Density & $\mathrm{g} / \mathrm{cm}^{3}$ & 1,27 & 1,19 & 1,36 \\
\hline 4 & Porositas & $\%$ & 49,26 & 46,73 & 48,55 \\
\hline 5 & Permeabilitas & $\mathrm{cm} / \mathrm{jam}$ & 29,97 & 46,12 & 18,03 \\
\hline
\end{tabular}

menjadi tidak efisien (Hanafiah 2007). Dapat dilihat nilai $\mathrm{pH}$ dan KTK di ketiga lokasi survei memiliki nilai yang berbeda, terutama pada lokasi Stadion Maguwoharjo yang memiliki nilai pH 5,40 dan KTK yang rendah yaitu 3,99. AgSource Laboratories (2012) menyebutkan bahwa pasir memiliki nilai KTK 1-5 me/100g.

Keasaman tanah pada Stadion Gelora Bung Karno dan Stadion Si Jalak Harupat memiliki nilai pH 6,60. Nilai ini mendekati pH normal $(7,0)$ dan berada dalam rentang $\mathrm{pH}$ tanah yang terdapat banyak nutrisi bagi pertumbuhan tanaman, sehingga dapat dikatakan bahwa media tanam pada kedua stadion tersebut memiliki tingkat kesuburan yang baik. Hal ini didukung dengan nilai KTK tanah di kedua stadion, yaitu pada Stadion Gelora Bung Karno sebesar 11,06 me/100g dan pada Stadion Si Jalak Harupat sebesar 16,08 me/100g. Nilai KTK yang cukup besar ini mempengaruhi
Stadion Maguwoharjo memiliki media tanam yang relatif bersifat asam. Keasaman tanah kurang dari 6,0 meningkatkan keterlarutan aluminium $(\mathrm{Al})$, mangan $(\mathrm{Mg})$, dan besi (Fe) yang bersifat racun dan membatasi pertumbuhan akar (Gardner et al 1991). Rendahnya nilai KTK ini menyebabkan sulitnya pertukaran unsur dalam tanah dan kurang tersedia untuk diserap oleh tanaman. Kedua faktor ini sangat mempengaruhi pertumbuhan tanaman dan cenderung menyebabkan defisiensi nutrisi pada tanaman.

\section{Konstruksi Media Tanam}

Jenis dan susunan material konstruksi lapangan sepakbola pada ketiga stadion lokasi survei berdasarkan hasil wawancara dapat lihat pada Tabel 7. Perbedaan konstruksi lapangan tentunya berpengaruh terhadap sifat fisik media tanam lapangan. Hal ini terlihat nyata yaitu pada tingkat permeabilitas di ketiga stadion 


\begin{tabular}{|c|c|c|c|c|c|}
\hline \multicolumn{6}{|c|}{ Tabel 7 Jenis dan susunan material konstruksi lapangan } \\
\hline \multicolumn{4}{|c|}{ 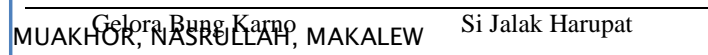 } & \multicolumn{2}{|c|}{ Maguwoharjo } \\
\hline Material & Ketebalan & Material & Ketebalan & Material & Ketebalan \\
\hline Rumput & $2 \mathrm{~cm}$ & Rumput & $2 \mathrm{~cm}$ & Rumput & $2 \mathrm{~cm}$ \\
\hline Pasir Pasang & $20 \mathrm{~cm}$ & Pasir+Sekam & $30 \mathrm{~cm}$ & Pasir Pantai & $30 \mathrm{~cm}$ \\
\hline Pasir Beton & $20 \mathrm{~cm}$ & Flanel & $0,5 \mathrm{~cm}$ & Geotekstil & $0,5 \mathrm{~cm}$ \\
\hline Geotekstil & $0,5 \mathrm{~cm}$ & Pipa Paralon & Q $10 \mathrm{~cm}$ & Koral 2/3 & $20 \mathrm{~cm}$ \\
\hline Kerikil & $20 \mathrm{~cm}$ & & & Tanah & $20 \mathrm{~cm}$ \\
\hline \multirow[t]{4}{*}{ Pipa Paralon } & Q $10 \mathrm{~cm}$ & & & Geotekstil & $0,5 \mathrm{~cm}$ \\
\hline & & & & Batu Split & $30 \mathrm{~cm}$ \\
\hline & & & & Pipa & Q $10 \mathrm{~cm}$ \\
\hline & & & & Paralon & \\
\hline
\end{tabular}

\begin{tabular}{|c|c|c|c|c|}
\hline \multicolumn{5}{|c|}{ Tabel 8 Pengukuran kualitas visual dan fungsional rumput lapangan sepakbola } \\
\hline \multirow{3}{*}{ Parameter } & \multirow{3}{*}{ Satuan } & \multicolumn{3}{|c|}{ Stadion } \\
\hline & & Gelora Bung & Si Jalak & Maguwoharjo \\
\hline & & Karno & Harupat & \\
\hline \multicolumn{5}{|l|}{ Kualitas Visual } \\
\hline Kepadatan & pucuk $/ 100 \mathrm{~cm}^{2}$ & 32 & 30 & 32 \\
\hline Warna Daun & Skor warna & 5 & 5 & 6 \\
\hline Tekstur & $\mathrm{cm}$ & 0,25 & 0,23 & 0,24 \\
\hline \multicolumn{5}{|l|}{ Kualitas Fungsional } \\
\hline Elastisitas & $\mathrm{cm}$ & 76,7 & 68,2 & 46,0 \\
\hline Hasil Pangkasan & $\mathrm{g} / 100 \mathrm{~cm}^{2}$ & 0,36 & 0,61 & 0,81 \\
\hline Panjang Akar & $\mathrm{cm}$ & 8,1 & 12,1 & 12,0 \\
\hline Berat Kering Akar & $\mathrm{g} / 100 \mathrm{~cm}^{2}$ & 0,8 & 1,4 & 1,0 \\
\hline
\end{tabular}

terlihat berbeda. Pada Stadion Maguwoharjo memiliki nilai permeabilitas paling kecil yaitu 18,03 $\mathrm{cm} /$ jam, dibandingkan dengan Stadion Gelora Bung Karno sebesar $29,97 \mathrm{~cm} /$ jam dan Stadion Si Jalak Harupat sebesar 46,12 cm/jam. Pada Stadion Si Jalak Harupat dengan konstruksi yang sederhana menyebabkan air lebih cepat hilang dibandingkan dua stadion lainnya karena pada dua stadion lain menggunakan konstruksi berlapis sehingga memperlambat hilangnya air.

\section{Kualitas Visual dan Fungsional}

Berdasarkan hasil pengamatan lapang diperoleh data pengukuran kualitas visual dan fungsional rumput lapangan sepakbola berdasarkan parameter yang telah ditentukan seperti yang terlihat pada
Tabel 8. Masing-masing variabel akan dijelaskan lebih lanjut.

\section{Kepadatan}

Ketiga stadion tersebut memiliki tingkat kepadatan pucuk yang memenuhi standar yaitu lebih dari 30 pucuk/100 cm2 yang berarti tingkat pertumbuhan rumput di ketiga stadion termasuk pertumbuhan yang baik. Area dengan lingkungan yang mendukung maka rumput dapat tumbuh dan berkembang dengan baik. Intensitas pemeliharaan juga akan mempengaruhi pertumbuhan dan kepadatan rumput. Stadion Gelora Bung Karno memiliki intensitas pemeliharaan yang lebih tinggi dibandingkan dengan dua stadion lainnya. Stadion Si Jalak Harupat dan Stadion Maguwoharjo memiliki tingkat pemeliharaan relatif lebih rendah. Namun, gulma yang terdapat di Stadion Si Jalak Harupat lebih banyak sehingga mempengaruhi pertumbuhan rumput manila pada stadion tersebut.

\section{Warna Daun}

Warna merupakan salah satu indikator penilaian visual yang paling mudah dinilai. Menurut Brosnan dan Deputy (2008) rumput manila memiliki warna hijau tua (skor 5). Stadion Gelora Bung Karno dan Stadion Si Jalak Harupat memiliki rata-rata warna daun skor 5. Hal berbeda terjadi pada Stadion Maguwoharjo. Pada stadion tersebut memiliki warna daun hijau gelap dengan skor warna 6. Pada dasarnya warna hijau daun sangat dipengaruhi oleh klorofil daun. Lebih lanjut, dilakukan analisis daun di dalam laboratorium untuk mengetahui jumlah total klorofil daun (Tabel 9).

Jumlah total klorofil rata-rata paling tinggi dimiliki oleh contoh daun yang diambil dari Stadion Maguwoharjo. Salah satu faktor yang mempengaruhi kandungan klorofil daun rumput manila di Stadion Maguwoharjo tinggi adalah teknik pemupukan yang diterapkan. Teknik pemupukan yang dilakukan pada Stadion Maguwoharjo yaitu memberikan pupuk nitrogen sebanyak 49,8 g/m2, fosfor sebanyak 31,2 g/m2, dan kalium sebanyak 9,6 $\mathrm{g} / \mathrm{m} 2$ setiap tiga bulan. Berdasarkan jumlah pupuk yang diberikan dapat dilihat bahwa pihak pengelola memberikan pupuk yang mengandung nitrogen (N) dalam jumlah yang cukup tinggi. Sumber pupuk $\mathrm{N}$ yang diberikan yaitu berasal dari pupuk NPK, urea, dan ZA. Hal ini dapat dinyatakan sebagai pemborosan pupuk dibandingkan dengan standar pemupukan rumput manila yang disebutkan oleh Brosnan dan Deputy (2008) sebesar $4,84 \mathrm{~g} / \mathrm{m} 2 \mathrm{~N}$ setiap 3 bulan.

\section{Tekstur}

Tekstur rumput menunjukkan penilaian kasar atau halusnya karakter fisik hamparan rumput 
yang terlihat secara visual. Ketiga stadion memiliki tekstur daun tidak termasuk dalam standar tekstur daun yang disebutkan oleh Patton (2010) sebesar kurang dari $2 \mathrm{~mm}$. Menurut hasil pengamatan lapang rumput manila (Zoysia matrella) memiliki ukuran daun lebih dari 2 mm. Perbedaan ukuran tekstur daun pada kondisi lapang dan standar yang disebutkan dapat disebabkan oleh perbedaan kondisi cuaca dan iklim lingkungan tumbuh rumput manila. Standar yang disebutkan oleh Patton mengacu pada pertumbuhan dan perkembangan rumput Z. matrella yang ditanam di Amerika dengan jenis iklim subtropis, sedangkan Indonesia memiliki iklim tropis dengan tingkat curah hujan yang tinggi sehingga akan mempengaruhi pertumbuhan dan perkembangan rumput manila. Selain itu, pemberian pupuk juga dapat mempengaruhi pertumbuhan daun. Gardner et al (1991) menyebutkan pemupukan $\mathrm{N}$ mempunyai pengaruh nyata terhadap perluasan daun, terutama pada lebar dan luas daun.

\section{Elastisitas}

Hasil pengukuran pantulan di ketiga stadion menunjukkan hasil yang cukup berbeda. Standar elastisitas rumput terhadap pantulan bola menurut FIFA (2012) sebesar 50-100 $\mathrm{cm}$, dengan nilai optimal pantulan 60-85 cm. Stadion Gelora Bung Karno dan Stadion Si Jalak Harupat memiliki nilai rata-rata pantulan yang memenuhi standar FIFA dan keduanya memiliki jarak pantulan bola dalam jangkauan optimum. Hal berbeda terlihat pada Stadion Maguwoharjo yang dengan pantulan relatif rendah sehingga tidak memenuhi standar. Jarak pantulan bola yang berbeda ini dipengaruhi oleh jenis media tanam yang digunakan pada Stadion Maguwoharjo. Stadion ini menggunakan media tanam pasir pantai yang memiliki ukuran partikel lebih kecil (< $1 \mathrm{~mm})$ dibandingkan pasir yang digunakan pada dua stadion yang lainnya (1 $\mathrm{mm})$, serta memiliki kandungan liat yang rendah sehingga bersifat sangat remah karena tidak menempel satu dengan lainnya. Hal ini menyebabkan media tanam di Stadion Maguwoharjo bersifat empuk sehingga mempengaruhi pantulan bola.

\section{Hasil Pangkasan (Yield)}

Berdasarkan hasil pengukuran laboratorium diketahui bahwa Stadion Maguwoharjo memiliki nilai berat kering pucuk tertinggi dibandingkan dua stadion yang lain, yaitu rata-rata seberat $0,81 \mathrm{~g} / 100$ cm2. Namun, nilai berat kering pucuk ini berbanding terbalik dengan kondisi kesuburan tanah Stadion Maguwoharjo yang memiliki $\mathrm{pH}$ masam dan memiliki nilai KTK rendah. Tingginya nilai berat kering pucuk pada stadion ini dipengaruhi oleh teknik pengelolaan, terutama pada kegiatan pemangkasan. Pada saat penelitian ini dilakukan dan sampel pucuk diambil, kondisi lapangan rumput sudah lama tidak dilakukan pemangkasan. Stadion Gelora Bung Karno memiliki ratarata berat kering pucuk sebesar 0,36 $\mathrm{g} / 100 \mathrm{~cm} 2$ dan Stadion Si Jalak Harupat memiliki rata-rata berat kering pucuk sebesar 0,61 g/100 $\mathrm{cm} 2$. Perbedaan jumlah berat kering pucuk pada kedua stadion ini dipengaruhi oleh kondisi kesuburan tanah di kedua lokasi tersebut. Pada Stadion Si Jalak Harupat hasil uji laboratorium menyatakan bahwa media tanam memiliki nilai KTK yang lebih tinggi dibandingkan dengan media tanam pada Stadion Gelora Bung Karno.

\section{Panjang Akar}

Rumput manila pada Stadion Si Jalak Harupat dan Stadion Maguwoharjo memiliki rata-rata panjang akar yang tidak berbeda. Pada Stadion Si Jalak Harupat pertumbuhan panjang akar dipengaruhi oleh tingkat kesuburan media tanam yang dicampur dengan sekam yang menjadi sumber bahan organik. Selain itu, teknik pemupukan pada Stadion Si Jalak Harupat rumput diberi pupuk sebanyak $40 \mathrm{~g} / \mathrm{m} 2$. Panjang akar di Stadion Maguwoharjo dipengaruhi oleh jenis media tanam yang digunakan berupa pasir pantai yang sangat remah sehingga memudahkan pertumbuhan dan perkembangan akar. Selain itu, defisiensi unsur hara yang terjadi pada stadion ini juga dapat memicu pertumbuhan akar. Akar tumbuh memanjang dalam usaha mencari sumber nutrisi. Stadion Gelora Bung Karno memiliki ukuran panjang akar yang paling pendek dibandingkan dengan dua stadion yang lainnya. Hal ini dipengaruhi oleh pemberian pupuk yang lebih sedikit dibandingkan dengan dua stadion lainnya.

\section{Berat Kering Akar}

Pada Stadion Si Jalak Harupat yang menggunakan media tanam pasir dicampur sekam memiliki berat kering akar yang paling tinggi dibandingkan dua stadion lainnya. Hal ini terkait dengan nilai KTK yang dimiliki Stadion Si Jalak Harupat paling tinggi sehingga nutrisi dan hara yang dibutuhkan bagi pertumbuhan rumput lebih banyak tersedia. Meskipun nilai KTK media tanam di Stadion Maguwoharjo sangat rendah namun jenis media tanam yang digunakan merupakan pasir pantai yang memiliki tekstur remah karena rendah mengandung liat sehingga memudahkan akar untuk tumbuh karena banyak ruang pori tanah yang dapat ditembus oleh akar sehingga pertumbuhan akar semakin banyak. Hal ini juga terkait dengan fungsi akar untuk mendapakan nutrisi bagi pertumbuhan rumput. Pada Stadion Gelora Bung Karno memiliki berat kering akar paling rendah. Hal ini dapat disebabkan oleh media tanam yang digunakan yaitu pasir pasang. Ukuran material pasir pasang tentunya lebih besar dibandingkan ukuran pasir pantai, dan intensitas penggunaan Stadion Gelora Bung Karno yang cukup tinggi menyebabkan media tanam lebih padat, serta dosis pupuk yang diberikan paling rendah diantara dua stadion lainnya.

Pemeliharaan Rumput 
Pemeliharaan rumput lapangan sepakbola pada ketiga stadion berdasarkan hasil wawancara dapat dilihat pada Tabel 10. Kegiatan pemupukan pada ketiga stadion terlihat berbeda pada jenis pupuk dan dosis yang diberikan serta waktu pemupukan. Tipe pupuk yang diberikan merupakan pupuk slow release. Hal ini mendukung pertumbuhan rumput lebih baik dibandingkan penggunaan pupuk quick release (Nasrullah dan Tunggalini 2000). Pemangkasan pada Stadion Gelora Bung Karno dan Stadion Si Jalak Harupat dilakukan secara rutin setiap minggu, namun pemangkasan pada Stadion Maguwoharjo intensif dilakukan memiliki pH dan KTK tertinggi, sedangkan Stadion Maguwoharjo memiliki $\mathrm{pH}$ dan KTK terendah. Pengelola Stadion Si Jalak Harupat menambahkan sekam sebagai campuran media tanam. Pemupukan pada ketiga stadion menerapkan dosis dan waktu pemberian yang berbeda. Pada Stadion Maguwoharjo terlihat adanya pemborosan pupuk, disebabkan oleh jenis pupuk yang diberikan beragam, dosis yang cukup tinggi, dan intensitas penerapan pupuk yang cukup tinggi. Jika dikaitkan dengan kesuburan media tanam, pemupukan yang dilakukan tidak efektif diserap oleh tanaman. Secara umum, pemangkasan pada ketiga stadion menerapkan ketinggian yang sama 2 cm. Perbedaan pemangkasan

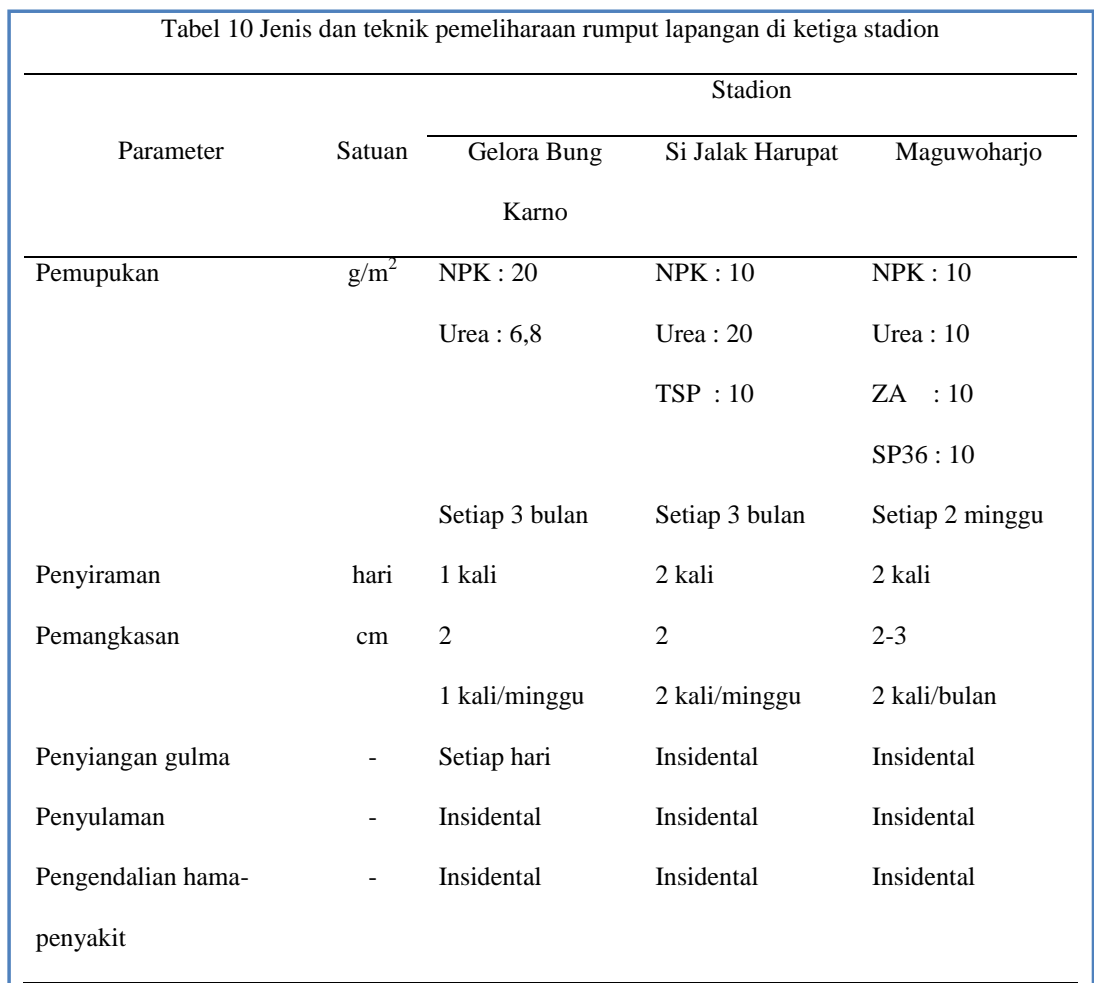

hanya pada minggu-minggu pertandingan. Penyiangan gulma rutin dilakukan pada Stadion Gelora Bung Karno sedangkan pada kedua stadion lainnya penyiangan dilakukan secara insidental.

\section{SIMPULAN}

Konstrukasi media tanam pada ketiga stadion memiliki komposisi yang berbeda, namun ketiganya menggunakan media tanam pasir sebagai media tumbuh rumput manila. Stadion Si Jalak Harupat terdapat pada teknik dan jadwal pemangkasan.

Hasil pengukuran kualitas visual dan fungsional di ketiga stadion menunjukkan bahwa Stadion Maguwoharjo memiliki kualitas lapangan yang lebih rendah dibandingkan dua stadion lainnya. Hal ini disebabkan oleh kondisi media tanam lapangan yang kurang subur sehingga mempengaruhi pertumbuhan dan perkembangan rumput Zoysia matrella. Dari tujuh variabel pengamatan, Stadion Gelora Bung Karno dan Si Jalak Harupat memenuhi empat kriteria standar, yaitu kepadatan tunas, warna daun, elastistas, dan panjang akar. Sedangkan Stadion Maguwoharjo hanya memenuhi dua kriteria standar, yaitu kepadatan tunas dan panjang akar.

\section{Saran}

Perlu dilakukan pengapuran pada media tanam Stadion Maguwoharjo untuk meningkatkan $\mathrm{pH}$ tanah. Selain itu, dapat ditambahkan kompos atau zeolit pada media tanam untuk meningkatkan KTK tanah sehingga nutrisi yang diberikan lebih mudah diserap dan dimanfaatkan oleh tanaman. Pemeliharaan lapangan berupa penyiangan gulma sebaiknya dilakukan secara rutin untuk menjaga kualitas rumput lapangan dari gulma, karena gulma merupakan pesaing rumput manila dalam penyerapan nutrisi yang diberikan. Waktu pemangkasan juga penting diperhatikan, kualitas rumput lapangan yang baik dipengaruhi oleh pemangkasan yang teratur dan rutin setiap minggu.

\section{DAFTAR PUSTAKA}

AgSource Laboratories. 2012. Soil Cation Exchange Capacity (CEC). Lincoln (US): Cooperative Resources International.

Barton L, Colmer TD. 2006. Irrigation and Fertiliser Strategies for Minimising Nitrogen Leaching from Turfgrass. Agricultural Water Management 80:160-175.

Brosnan, JT dan Deputy, J. 2008.Zoysiagrass [catatanpenelitian].Manoa : college of tropical agriculture and human resources. 1-6.

Christians, N. 2004.Fundamental of turfgrass management, Second Edition. New Jersey: John Wiley \& Sons, Inc.

Emmons R. 2000. Turfgass Science and Management, Third Edition. New York (US): Delmar, Thomson Learning.

Fatmasari, YD. 2011. Evaluasikualitasfungsionaldan visual lapangan bola yang dipakaiuntukkompetisiliga super [Skripsi]. Bogor: InstitutPertanian Bogor.

[FIFA] Federation Internationale de Soccer Association.2012 .FIFA Quality Concept for Soccer Turf. Switzerland: FIFA

Gardner FP, Pearce RB, Mitchell RL. 1991. FisiologiTanamanBudidaya. SusiloHerawati, penerjemah. Jakarta: 
UI-Press. Terjemahandari: Culture plants phsyology.

Hanafiah, KA. 2007. Dasardasarilmutanah. Jakarta: PT Raja GrafindoPersada.

Lasamadi RD, Malalantang SS, Rustandi, Anis SD.

2013.PertumbuhandanPerkembang anRumput Gajah Dwarf (Pennisetumpurpureum cv. Mott) yang DiberiPupukOrganikHasilFermentasi EM4.JurnalZootek 32(5):158-171.
NasrullahN,Tunggalini NKW. 2000. PengaruhPemupukan Urea dan Nitrogen Slow Release terhadapPertumbuhandanKualitasRumputLapangan Golf.BuletinAgronomi 28(2):62 65.

Patton, A. 2010. Selecting Zoysiagass cultivars: turf quality and stress tolerance [catatanpenelitian]. GCM: 9095.

Puhalla J, Krans J, Goatley M. 1999. Sports fields: a manual for design con- struction and maintenance. New Jersey: John Wiley \& Sons, Inc.

Ronkainen J, Osei-Owusu P, Webster J, Harland A, Roberts J. 2012.Elite Player Assessment of Playing Surface for Football.Procedia Engineering 34:837-842.

Sutanto R. 2005. Dasar-Dasarllmu Tanah: KonsepdanKenyataan. Yogyakarta (ID): Kanisius. 